\title{
Embedding YouTube Videos and Interactions in PowerPoint Using Office Mix for Adaptive Learning in Support of a Flipped Classroom Instruction
}

\section{Prof. John M. Santiago Jr, Colorado Technical University}

Professor John Santiago has been a technical engineer, manager, and executive with more than 26 years of leadership positions in technical program management, acquisition development and operation research support while in the United States Air Force. He currently has over 16 years of teaching experience at the university level and taught over 40 different graduate and undergraduate courses in electrical engineering, systems engineering, physics and mathematics. He has over 30 published papers and/or technical presentations while spearheading over 40 international scientific and engineering conferences/workshops as a steering committee member while assigned in Europe. Professor Santiago has experience in many engineering disciplines and missions including: control and modeling of large flexible space structures, communications system, electro-optics, high-energy lasers, missile seekers/sensors for precision guided munitions, image processing/recognition, information technologies, space, air and missile warning, missile defense, and homeland defense.

His interests includes: interactive multimedia for e-books, interactive video learning, and 3D/2D animation. Professor Santiago recently published a book entitled, "Circuit Analysis for Dummies" in 2013 after being discovered on YouTube. Professor Santiago received several teaching awards from the United States Air Force Academy and CTU. In 2015, he was awarded CTU's Faculty of the Year for Teaching Innovations. Professor Santiago has been a 12-time invited speaker in celebration of Asian-Pacific American Heritage Month giving multi-media presentations on leadership, diversity and opportunity at various military installations in Colorado and Wyoming.

\section{Dr. Jing Guo, Colorado Technical University}

Dr. Jing Guo is a Professor in Engineering Department at Colorado Technical University. She is the course director in circuits and electronics area. She taught variety of underrated and graduate courses including capstone design in Electrical and Computer Engineering area. 


\title{
Embedding YouTube Videos and Interactions in PowerPoint Using Office Mix for Adaptive Learning in Support of a Flipped Classroom Instruction
}

\author{
John M. Santiago, Jr., Ph.D. and Jing Guo, D.Eng. \\ Colorado Technical University (CTU), College of Engineering, Colorado Springs, CO
}

\section{Background on Using Camtasia and YouTube}

Shortly after retiring from the United States Air Force in 2003, the Professor Santiago investigated the viability of teaching engineering content and creating multimedia e-books for online delivery. He learned several skills in producing STEM content. These skills include: website development, WordPress for blogging, 2D-3D animation, internet marketing and search engine optimization, graphics and instructional design and use of e-learning techniques and tools. Most of the content is primarily focused in electrical engineering. He developed an interactive website back in 2004 to create and test the multimedia content. During that time, he discovered Camtasia produced by TechSmith. Camtasia became a must-have tool for developing interactive and multimedia content. Unfortunately, he found out you need a website to take advantage of Camtasia's vast capabilities. It has many interactive features to promote viewer engagement. Table 1 lists key features of Camtasia. He assumes that most educators do not have a website for testing teaching methods.

\begin{tabular}{|c|c|c|}
\hline $\begin{array}{l}\text { Camtasia } \\
\text { Feature }\end{array}$ & Description & Educational Benefit \\
\hline \multirow[t]{2}{*}{ a } & Hot Spots: & $\begin{array}{l}\text { Students can choose a particular learning path and interact with video by clicking on buttons or } \\
\text { characters. }\end{array}$ \\
\hline & & $\begin{array}{l}\text { Create attractive PowerPoint slides and import with Camtasia. Allows anything to be clickable } \\
\text { so learner can move seamlessly to a new screen or even outside the video to additional learning } \\
\text { materials. }\end{array}$ \\
\hline b & Add-in to PowerPoint & $\begin{array}{l}\text { Screen Capture of PowerPoint Presentation delivered in a micro-learning fashion and combined } \\
\text { with cursor highlighter to keep learner attentive. }\end{array}$ \\
\hline c & $\begin{array}{l}\text { Ability to Collect and } \\
\text { Report Test Scores }\end{array}$ & $\begin{array}{l}\text { Create Quiz and Collect Results via email. Organizes them and sends a daily report of how } \\
\text { students are doing. }\end{array}$ \\
\hline d & $\begin{array}{l}\text { Multiple video } \\
\text { Windows or Tracks }\end{array}$ & $\begin{array}{l}\text { Keep Learners attentive. Display screen recording inside one window, presenter talking in } \\
\text { another and an animation to go along with the screen recording in the third. }\end{array}$ \\
\hline e & Green-screen removal & $\begin{array}{l}\text { Overlay videos to create interesting learning scenarios. Need to avoid too many moving parts } \\
\text { that will distract the learner }\end{array}$ \\
\hline f & Call-outs & $\begin{array}{l}\text { Can be used to call attention to the learner on a key concept or call-to-action. Like calling } \\
\text { attention to the learner on an area on the video }\end{array}$ \\
\hline B & Cursor highlighter & $\begin{array}{l}\text { Can be used to keep interest to follow the animation of a hand-written sketch or text similarly } \\
\text { found in a whiteboard presentation...has potential for a Dopamine effect. }\end{array}$ \\
\hline h & Pan and Zoom & $\begin{array}{l}\text { Use to highlight an area of interest in the screen and to create variety in what's being displayed } \\
\text { and keep learner attentive }\end{array}$ \\
\hline 1 & Markers & Use to create a table of contents of portions of a long video \\
\hline
\end{tabular}

Table 1. Features of Camtasia to Promote Create and Engage Content to Viewers

Camtasia is both a screen capture and video editing software. Camtasia was targeted for the education market. The application evolved from being a program for software demonstrations back in 2005 to a full-featured educational tool in 2015. Screen recording with Camtasia 
requires a relatively small initial investment and logistics when compared to a video recording studio.

After creating hundreds of videos using PowerPoint and Camtasia, the Professor created personal YouTube Channels 1 and 2 of Table 2, back in 2008. The videos were mostly screen recordings where the he wrote on a laptop screen. The simple screen recordings mimic a short whiteboard lectures conducted in a traditional face-to-face classroom. The results and experience were shared with the engineering faculty and colleagues.

The number of views and the number of subscriptions indicate some level of interest in the content. However, the number of videos and the age of the channel should be considered when looking at the number of subscriptions. It takes time to build a subscriber base, especially with today's increased competition.

\begin{tabular}{|l|c|c|c|c|}
\hline \multicolumn{1}{|c|}{ Channel } & $\begin{array}{c}\text { Number of } \\
\text { Views }\end{array}$ & $\begin{array}{c}\text { Number of } \\
\text { Subscribers }\end{array}$ & $\begin{array}{c}\text { Number } \\
\text { of Videos }\end{array}$ & Creation Date \\
\hline $\begin{array}{l}\text { Channel 1: Variety of EE Topics } \\
\text { (includes DC circuit Analysis as well) }\end{array}$ & $3,439,118$ & 7613 & 161 & 19 Jan 2008 \\
\hline $\begin{array}{l}\text { Channel 2: Primary focus is on Circuit } \\
\text { analysis }\end{array}$ & 890,006 & 2717 & 51 & $21 \mathrm{Feb} 2009$ \\
\hline $\begin{array}{l}\text { Channel 3: Introduction to Engineering } \\
\text { and other topics }\end{array}$ & 21,733 & 71 & 106 & 25 Mar 2015 \\
\hline
\end{tabular}

Table 2. Selected YouTube Channels as of 8 Jan 2017.

Table 3 attempts to provide a sample of video types to increase viewer engagement, including: PowerPoint animations, 'how-to' videos of engineering tools, embedded engineering simulations, and green-screen techniques. Most of these videos are 5-10 minutes long. In terms of likes and dislikes, the videos appear to be effective for most viewers. The Professor __ not only tested topics in circuit analysis, but also created videos for digital signal processing, analog communications, signal and systems, Laplace and z-transforms and others.

\begin{tabular}{|c|c|c|c|c|}
\hline Video Title/Link & $\begin{array}{c}\text { Date } \\
\text { Uploaded } \\
\text { (length min:sec) }\end{array}$ & $\begin{array}{c}\text { Number of } \\
\text { Views }\end{array}$ & Likes & Dislikes \\
\hline $\begin{array}{l}\text { 1. Signal Processing Tutorial: Discrete-Time } \\
\text { Convolution Examples (Inverse z-Transform) }\end{array}$ & $\begin{array}{c}20 \text { Apr } 2008 \\
(9: 53)\end{array}$ & 29,648 & 66 & 2 \\
\hline $\begin{array}{l}\text { 2. Matlab Examples - Review of Discrete Convolution } \\
\text { using Matlab }\end{array}$ & $\begin{array}{l}27 \text { Apr } 2009 \\
(7: 36)\end{array}$ & 41,279 & 63 & 5 \\
\hline 3. $\quad$ Matlab Tutorial - Amplitude Modulation & $\begin{array}{l}25 \text { Jun } 2008 \\
(9: 36)\end{array}$ & 114,024 & 166 & 13 \\
\hline 4. Operational Amplifier Tutorial - Basic Op Amp (Part) & $\begin{array}{c}1 \text { Mar } 2009 \\
(9: 50)\end{array}$ & 248,703 & 514 & 24 \\
\hline $\begin{array}{l}\text { 5. Simulink / Matlab Video Tutorial and Example - Low } \\
\text { Pass Filter - Bode Plots (Part 2) }\end{array}$ & $\begin{array}{c}3 \text { Jul } 2009 \\
(5: 10)\end{array}$ & 203,803 & 182 & 8 \\
\hline $\begin{array}{l}\text { 6. Thevenin \& Norton Examples - Tutorial on Thevenin } \\
\text { Equivalent Circuit Theory - Part } 1\end{array}$ & $\begin{array}{c}\text { 6 Mar } 2009 \\
(5: 56)\end{array}$ & 146,531 & 162 & 28 \\
\hline $\begin{array}{l}\text { 7. Electric Current: Define Electric Current Flow with A } \\
\text { Water Analogy }\end{array}$ & $\begin{array}{l}5 \text { May } 2015 \\
(4: 37)\end{array}$ & 6451 & 15 & 1 \\
\hline
\end{tabular}

Table 3. Selected and Sample Videos Using Camtasia as of 8 Jan 2017. 
Based on the positive results with using Camtasia and YouTube, the Professor Santiago shared his experience with full-time faculty. This was also in response to the University's task in 2015 to create online engineering courses.

\section{Summary of Past Results using PowerPoint, Camtasia and YouTube Videos to Create an 'Introduction to Engineering (EE110)' Course}

In 2015, the Colorado Technical University started an initiative to deliver engineering courses online. Senior leadership wanted to expand its undergraduate and graduate engineering programs. The engineering faculty decided to develop a freshman-level course entitled, Introduction to Engineering (EE110) using a flipped classroom approach ${ }^{1-3}$.

EE110 provides the beginning engineer with fundamental knowledge and skills associated with the electrical or computer engineering professions. Table 1 illustrates the lab assignments that the students must complete during class. It will introduce common electronic components, basic circuit configurations, and laboratory instruments. Bench practices and lab reports will be introduced along with computer aided analysis. The objectives of the course expect students to systematically solve problems; demonstrate safe habits, identify and apply electronic theory, circuit components, and equipment; and identify and apply basic logic gates.

The faculty learned about the basic use of Camtasia and YouTube. Professor Santiago also created a College of Engineering channel identified as Channel 3 of Table 2. The channel's title is "STEM Videos for the Flipped Classroom". It was used to test the viability of the flipped classroom for EE110.

In 2016, Professor Guo taught the flipped classroom for EE110 during three quarters: Winter, Spring, and Fall Quarters. The students needed to do assigned tasks, including: watch videos, do assigned readings and homework, and do weekly quizzes before coming to class. Otherwise, they may have trouble doing the weekly lab experiments. Table 4 lists the lab assignments for each week. When they came to class, there were no hour-long lectures in EE110. Classroom time was reserved to address student questions on the multimedia content, homework or lab assignments.

\begin{tabular}{|l|l|}
\hline Week \# & Lab Assignments \\
\hline Week01 & Circuits Laboratory Introduction \\
\hline Week03 & Digital I/O Circuits \\
\hline Week04 & Basic Gates Verification \\
\hline Week05 & Digital Simplification \\
\hline Week06 & Ohms Law \\
\hline Week07 & Complex Circuit Analysis \\
\hline Week08 & RC Circuits Multisim Simulation \\
\hline Week09 & Function Generator Assembly \\
\hline Week10 & Function Generator Testing \\
\hline
\end{tabular}

Table 4. EE110 Lab Schedule

Student feedback from end-of-course surveys showed a positive learning experience, especially the hands-on lab experiments ${ }^{1-3}$. The successful completion of lab assignments show that the 
multimedia content and weekly online quizzes prepared students to successfully complete the lab experiments.

\section{Flipped Classroom Approach: Summary of Results from Winter 2016 to Fall 2016}

Table 5 shows the survey results for the flipped classroom when compared to the traditional face-to-face class (or ground) for EE110. The left column shows the grade distribution, average percentage grade for the class with and without students who received an F, instructor, and delivery method. Instructor 1 (one of the authors) taught all the flipped classrooms and one ground (or traditional face-to-face) class for comparison. Since full-time faculty were creating the online multimedia and interactive content for EE110 during 2015, several instructors taught the ground courses shown in the last three columns. The percentage of grades serves as a comparison between the flipped classroom and the traditional face-to-face instruction of with and without Fs (highlighted in yellow) are given. The results show three quarters of teaching EE110 using the flipped classroom approach. Table 5 shows the grade percentages for the flipped classroom or ground instruction. As found in the 2016 Winter Quarter survey ${ }^{1-3}$ the students who received Fs resulted from lack of classroom attendance and lack of submitted work. Based on a student comment, the students who received Fs are not comfortable with the flip classroom approach and prefer the traditional face-to-face teaching. The flipped classroom approach places more responsibility on the students which may be too much for students who are more comfortable with the ground approach.

\begin{tabular}{|c|c|c|c|c|c|c|c|}
\hline & Fall2014 & Win2016 & Sum2016 & Fall2016 & Fall2014 & Spr2015 & Fall2015 \\
\hline A & 5 & 3 & 1 & 3 & 1 & 2 & 3 \\
\hline B & 2 & 1 & 2 & 1 & 4 & 2 & 5 \\
\hline C & 1 & 1 & 1 & 1 & 4 & 1 & \\
\hline D & 1 & 1 & 1 & & & & \\
\hline F & & 3 & 2 & 2 & 82.7 & 88.1 & 87.7 \\
\hline w/o F & 90.6 & 85.5 & 83.0 & 88.8 & & \\
\hline w/F & 85.2 & 66.7 & 67.0 & 70.7 & & \\
\hline Instructor & 1 & 1 & 1 & 1 & Ground & Ground & Ground \\
\hline
\end{tabular}

Table 5. Summary of Grade Percentages from 2016 Winter Quarter through 2016 Fall Quarter (ground delivery refers to face-to-face instruction).

As part of continuous improvement process, updated videos were posted afterwards when the full-time faculty gained experience using Camtasia. Various technologies for improvement in delivery include: (1) using word document with links to YouTube videos followed by with quiz questions in the first offering; (2) adding Google Docs (or Google Forms) with embedded YouTube Videos and quizzes in the next class session; and (3) including both Google Docs and interactive videos in the third. End-of-Course Surveys consistently show that the students enjoyed the weekly hands-on labs. After the third class offering, an additional survey of student 
experience with the new technologies was conducted. The results reflected a positive student experience with the course delivery.

During the third offering (2016 Fall Quarter), a survey was conducted with five students from EE110 and four students from an Advanced Circuit Analysis course (EE 341) to assess the teaching effectiveness thus far. This diversity of students also provided comments on the teaching approach using interactive multimedia and its frequent testing.

The quantitative results of the teaching methods are summarized and shown in Table 6 . The 2016 results from the student surveys show regular satisfaction with the flipped classroom approach $^{1-3}$. However, one student commented in the Winter 2016 feedback survey that a few students did not like the flipped classroom approach and are more comfortable with the traditional face-to-face method of instruction ${ }^{1-3}$. This may explain the increase number of Fs shown in Table 5.

\section{Survey Questions for EE110, Introduction to Engineering \\ (1 - Strongly Disagree, 2 - Disagree, 3-Neutral, 4-Agree, 5-Strongly Disagree)}

1. The teaching methods in this course are effective.

$\begin{array}{lllll}1 & 2 & 3 & 4 & 5\end{array}$

2. Interactive video with embedded knowledge checks enhance engagement for the student when viewing the video.

3. Quizzes in Google Forms (or Docs) format enhance engagement for the student when viewing the video and then answering questions.

4. The interactive video and assessment approach (Google Forms) provided an effective approach to teach engineering topics for either the traditional face-to-face teaching or online teaching

Table 6. Student Survey of Teaching Approach in 2016 Fall Quarter

Student comments are shown in Table 7 for Fall 2016 and are consistent with previous surveys. The comments from Questions 1 through 4 show that both Google Docs and interactive video were appreciated by the most of the students. One student comment said that more videos should be available for both face-to-face and online instruction. Another student commented that he would like to have more video lectures set up like this for other classes. Although the videos are relatively short (5 to 10 minutes as a goal), another student's mind began to wander and got distracted. This was a surprising comment to the authors. However, the same student commented that the frequent testing kept him engage. One of the authors briefly investigated the issue on 'mind wondering' and found a study to explain it. Here's a brief quote from a Harvard study about elearning when it comes to mind wandering 5 :

"It was surprising how high the baseline tendency to mind-wander is," Schacter said. "In our experiments, when we asked students if they were mind-wandering, they said yes roughly 40 percent of the time. It's a significant problem... It's not sufficient for a lecture to be short or to break up a lecture as we did in these experiments," Schacter said. "You need to have the testing. Just breaking it up and allowing them to do something else, even allowing them to re-study the 
material, does nothing to cut down on mind-wandering, and does nothing to improve final test performance. The testing is the critical component." The survey appears to help just the approach on frequent testing used in EE110. In addition, frequent assessments using PowerPoint help reinforce the concepts in video mini-lectures and is consistent with past studies $^{7,8,9}$.

1. The teaching methods in this course are effective:

The evaluations through the video really help to reinforce concepts covered in the lecture.

I liked the way that the lectures focused on just one or two points and thoroughly explained them. I also liked that if there was a topic that I did not understand immediately I could rewind the video and view the material again.

The teaching methods were as effective as they could be with out a face to face.

I enjoy the quiz style for the extra credit as well

2. Interactive video with embedded knowledge checks enhance engagement for the student when viewing the video: More video lectures should be setup like this.

I find that when I watch a long video or a video lecture it is easyfor my mind to wander or get distracted. I felt that the knowledge check kept my mind from wandering and helped me to focus on the topic main points of the topic.

The interactive part of the video greatly helps with keeping you engaged with the material.

\section{Quizzes in google forms format enhance engagement for the student when viewing the video and answering the} questions

The quiz question formats used are excellent and easy to understand.

I found that just knowing that there was going to be a quiz made me want to make sure I understood the topic at hand. I also thought that to see the material and then be given a question about it made sure that I was understanding what the main points were and that I understood the types of examples to displaymy knowledge. I also liked having the answers for questions that I missed so I could go back to the video or look in the book to find out how to get the correct answer. This gave me much more confidence in my understanding of the material.

\section{The interactive video and assessment approach (Google Forms)provided an effective approach to teaching} engineering topics for either the traditional face-to-face teaching or online teaching:

Both online and ground classes should have access to these videos. Doing so could allow more time for in class discussions on more complex topics.

This is definitely helpful since I have taken the EE110 and was required to watch the whole video and then answer the questions. I feel putting the questions in the video immediately after the topic is covered helps the user to retain the information better as well as stay engaged.

I thought that the interactive video and assessment approach did provide an effective approach to teaching the topic. I think that watching the videos combined with reading the book and completing homework will give the student a thorough understanding of the topic. I am primarily a ground student and I think that these interactive videos would be a valuable tool for a ground class also. I find that a student can never have enough resources to reinforce the knowledge given in class. If a student is having trouble grasping the concepts of a class fast enough these videos would be invaluable.

The videos would greatlyenhance a traditional class and definitely make online classes a more feasible option for online classes.

Although the google form learning style can be effective, sometimes it is possible for a student to pass without learning the material. Because of this, I believe that the interactive video learning style is more effective.

Table 7. Student Survey on Teaching Methods for 2016 Fall Quarter 
For online delivery, PowerPoint slides can be used to embed interactive videos with frequent testing. PowerPoint can serve as a document to explain and control the flow of content for a learning module. The authors have effectively used this approach for other courses during snow days when classes were cancelled.

For Question 3 of Table 7, the Google Docs approach evolve from using PowerPoint to deliver a series of embedded YouTube videos, followed with short quizzes. Google Docs is used to record quiz results after viewing a series of videos. The authors are currently investigating how to record quiz results within PowerPoint.

Embedding live webpages in PowerPoint can greatly enhance student engagement for both faceto-face or online instruction. The next section describes a new a free add-in for PowerPoint to further increase the learning experience.

For Question 4, interactive video received the most positive comments. The Google Docs and interactive video provided an effective approach per student comments.

\section{Adaptive Learning Using PowerPoint and the Office Mix Add-in}

Given the promising results from the flipped classroom during 2016, this section describes innovative ways of using PowerPoint for future online courses.

The College of Engineering and the University are geographically located in different states. The Learning Management System (LMS) and adaptive learning system (AL) are centrally managed by the University. The integration of engineering content with the LMS/AL required frequent coordination between the engineering faculty and the University's project manager.

Using PowerPoint and teleconferences provided project managers an explanation of how the engineering content should be taught and delivered. For example, Figure 1 provides one visual representation on how to deliver and integrate the engineering content with the University's AL software. Figure 1 consists of PowerPoint slides to create the flowchart. The University's AL platform is a presentation and analytics tool to track student progress for the educator. The AL

\section{Adaptive or Non-linear Learning Approach}

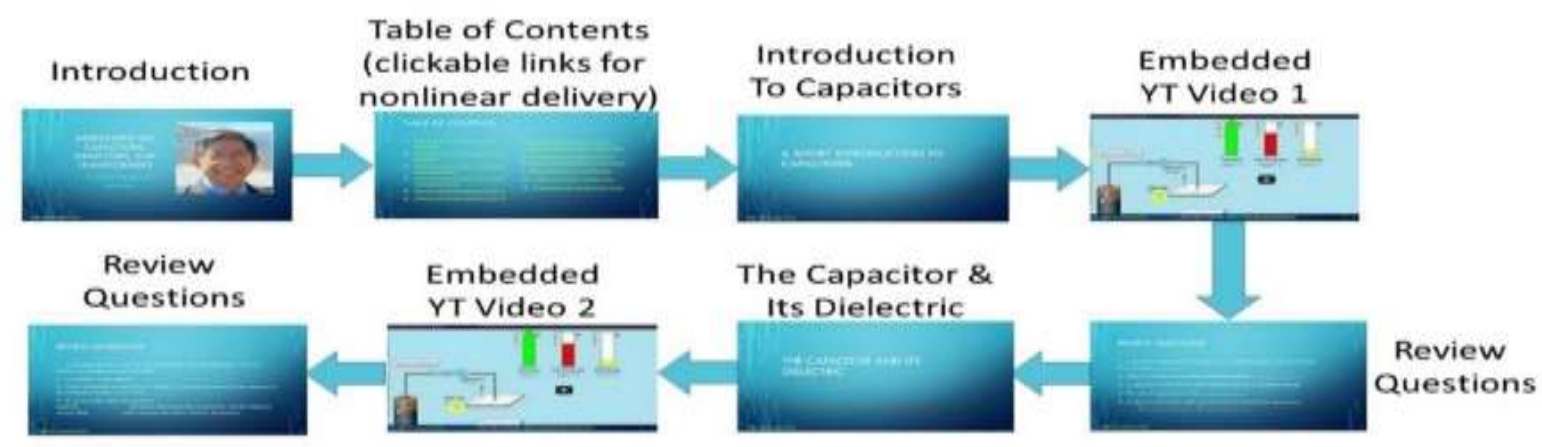

Figure 1. Sample Flowchart of PowerPoint Slides With a Series of Embedded YouTube and Short Assessment Quizzes Used in Introduction to Engineering. 
software was successfully applied for trigonometry and pre-calculus courses ${ }^{6}$. This is done by determining the student pre-determined knowledge state on a subject or topic. The AL platform provides personalized and customized learning for students. The students must respond through a series of pre-assessment questions to determine their knowledge state. Based on their answers, a customized learning map is created with learning nodes or modules. The platform creates individual learning nodes, or steps, for the student to ensure the understanding each element to a specific unit of work.

During the development of EE110, the engineering faculty found out that the multimedia content resulted in a large file size created with PowerPoint. The file sizes are too large to send by email. However, embedding YouTube videos on a PowerPoint slide, the file size of the e-book can be significantly reduced. For example, one set of videos in PowerPoint for an introductory course had a file size of $112 \mathrm{Mb}$. This large file size was too large to be sent by email. Using embedded YouTube videos within PowerPoint resulted in a file size of $1.2 \mathrm{MB}$. This 93-fold reduction of file size is small enough to email an entire learning module. On each slide with embedded videos, links to YouTube are given to Project Managers for them to download so they can integrate them to the AL platform.

The images of the flow diagram in Figure 1 were generated and saved using PowerPoint. Each PowerPoint slide can be saved as images to illustrate the workflow of the learning module. The arrangement of PowerPoint slides, contains a series of short videos and assessment quizzes. PowerPoint presentation has links to YouTube videos so that the Program Managers can download these videos. Figure 1 is like the workflow diagrams generated by the AL platform at the University.

PowerPoint can also serve as a simplified stand-alone Adaptive Learning Platform. Figure 1 provides a simple implementation of adaptive or nonlinear learning without the data analytics engine from the University's AL platform. This is helpful to test the instructional design of the learning module during a piloted course while the University's Program Managers integrate the content into their AL platform. The approach relies on the student to assess their understanding of the material through frequent testing found in the PowerPoint presentation.

By providing learning modules with branching in PowerPoint, the student can jump to various portions of the presentation. For example, Figure 1 shows a 'Table of Contents" found on slide 2. Students can have an option to select a subset of the 45-slide learning module if portions of the presentation are already familiar by the student.

Recently, Microsoft develop a free add-in called Office Mix. Since the authors delivered their lessons using PowerPoint, Office Mix can be used as a container to embed external and secured (https) web applications within a slide. Using this technique, the instructor or student does not need to jump between PowerPoint and various cloud-based applications or websites. Office Mix allows the educator to embed interactive learning modules from websites within PowerPoint. The approach is better than having a word document which has links to YouTube Videos and then jumping back to the word document to answer quiz questions which was initially used during 2016 Winter Quarter. 
The authors can embed interactive simulations within PowerPoint by using Office Mix. For example, there are numerous PhET simulations. PhET originally stood for "Physics Education Technology but expanded to other technical disciplines ${ }^{10}$. The PhET Interactive Simulations project at the University of Colorado Boulder creates free interactive simulations in math and science and was founded by Nobel Laureate Carl Wieman. PhET simulations are based on extensive education research to engage students through an intuitive, game-like environment. $\mathrm{PhET}$ simulations allow students to learn through exploration and discovery. One of the $\mathrm{PhET}$ simulations was used in EE110 to explain how to use a voltmeter and ammeter and how to connect circuits. Several other PhET simulations were also used in EE110 to create an interactive learning experience. Figure 1 shows YouTube videos on the use of PhET simulations.

With Office Mix, the instructor can embed quizzes with review questions on the slide. The educator can provide options for the novice learner to view several worked-out problems before taking an assessment quiz. By providing options for the e-learner, the educator provides control for the student allowing them to get engage with the content at their own pace. The e-learner makes a choice in viewing more videos before taking an assessment quiz to demonstrate their knowledge.

By using embedded videos and Office Mix, these tools offer instructors to present their material in engaging ways. Microsoft provided online help for the educator to get started through their gallery on the Office Mix site containing a series of tutorial Mixes, which can be viewed online, or downloaded and played on a wide range of devices.

After installing the Office Mix plug-in, the educator will find a new Mix tab in the PowerPoint ribbon. Figure 2 is an example embedded and interactive PhET simulation on the slide using

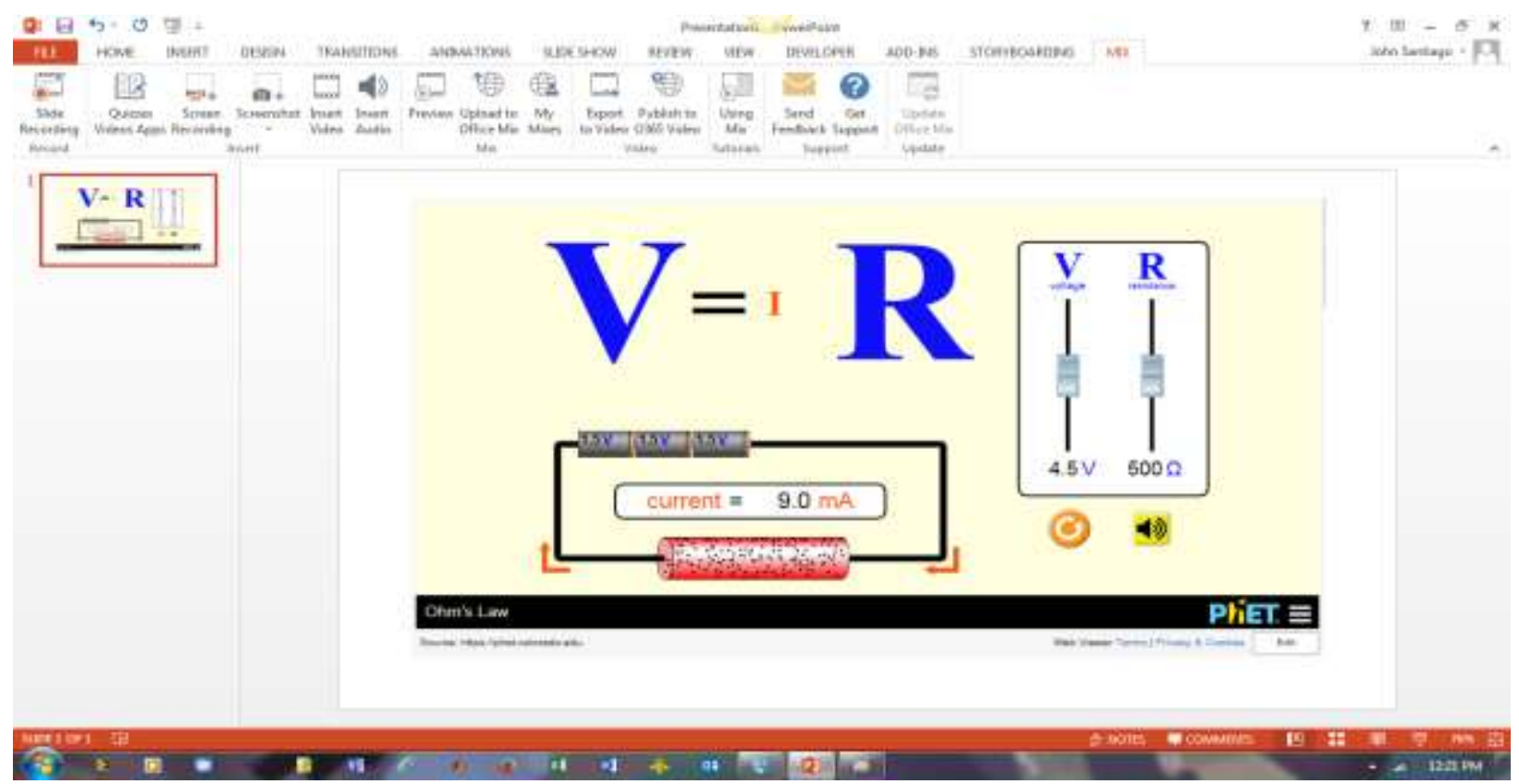

Figure 2. Embedded PhET Simulation and Interactive Model using Microsoft's Office Mix 
Office Mix. The PhET model is interactive to emphasize key concepts. After the instructor demonstrates how to do the simulation, the student can try it. The authors envision that more apps will be developed that's compatible with the Office Mix add-in. In the future, it may be possible that a cloud-based Matlab/Simulink, Labview or Pspice may be in the works that can communicate with this relatively new add-in.

For online delivery of advanced courses, students can use PowerPoint to record 5-minute video presentations. Video recordings of selected lab experiments verifies student understanding of the content and practice their communication skills. This type of reflection exercise emphasizes the need to summarize the experiments in a concise manner.

\section{Embedding Google Docs and Interactive Video with Office Mix Plus Visual Basic for Application}

Videos and weekly quizzes were given in EE110 to prepare the students for the weekly lab assignments. Figure 3 shows a screenshot of Google Docs. Figure 3 attempts to show a series of
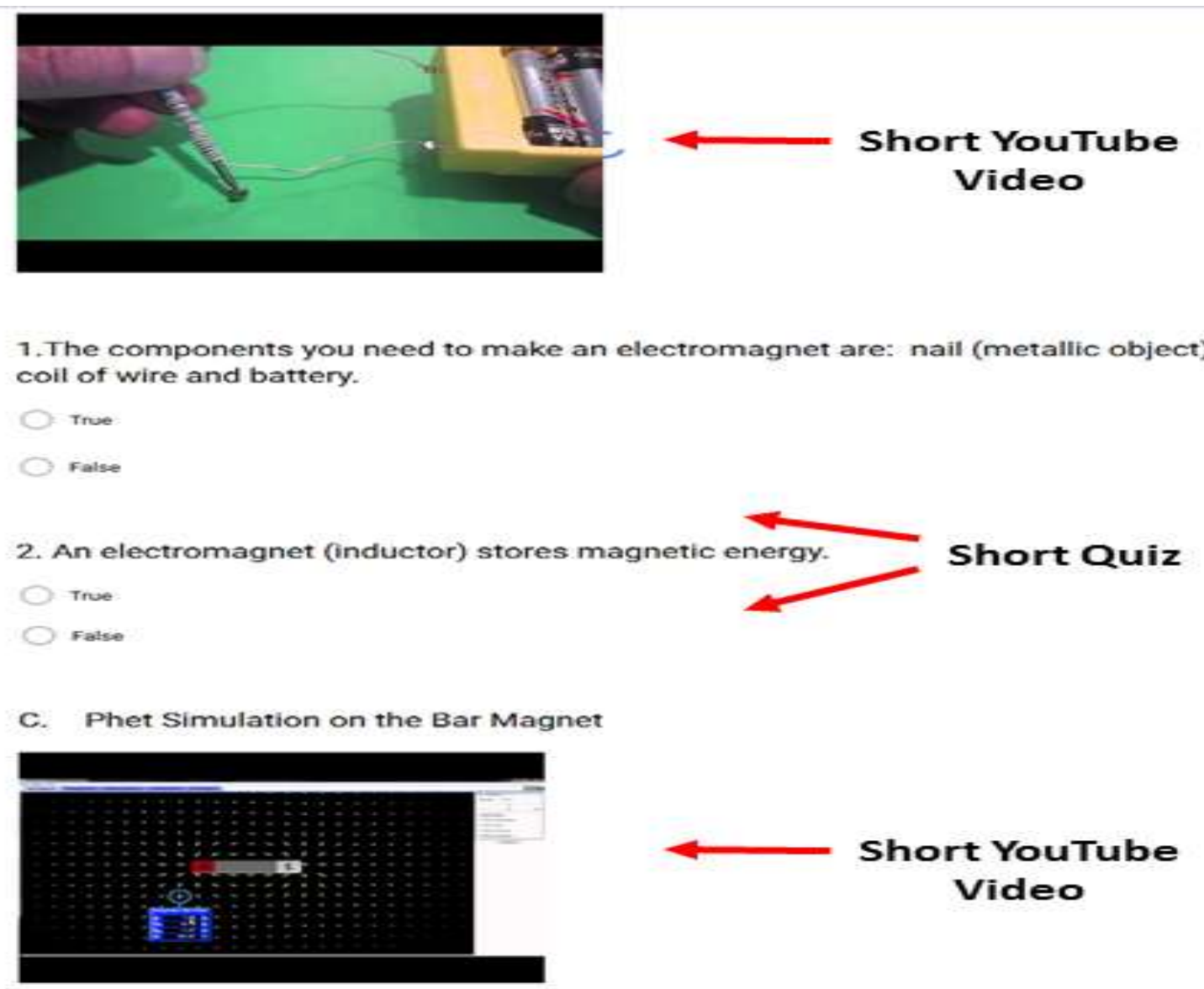

1. A permanent magnet has stationary fields just like an electromagnet with a

Figure 3. Screenshot of Google Docs with embedded YouTube videos and quiz questions 
videos followed with a quiz for each video. The authors attempted to embed Google Docs in PowerPoint using Office Mix. The authors were successful in embedding the Google Docs on the slide and could play the YouTube videos. Unfortunately, the authors were not able to answer quiz questions on the slide. The authors are currently investigating this issue and anticipates that future upgrades of Office Mix will resolve compatibility problems with Google Docs. The intent here is to provide an approach so that students do not have to jump back and forth between desktop and web-based applications.

Currently, the EE110 students are given links to Google Docs for the various learning modules.

The authors tried another approach using a website with blogging software. The website has a free eLearning software to create interactive videos to improve the learning experience. For example, Figure 4 depicts what is meant by an interactive video. Figure 4 shows screenshots of an interactive video before and after the student presses a quiz (or knowledge check button). The left screenshot of Figure 4 shows the display of an interactive view before a student presses a quiz or knowledge check button. When a quiz question appears, the video pauses signaling the student to answer the question. At the bottom of the left screenshot, knowledge checks appear throughout the video at various times. These knowledge checks provide the student a level of anticipation which engages the learner.

The right illustration of Figure 4 shows the display after the student clicks on the button. The student must respond to the question. After answering the question, the e-learner gets feedback. Also, each time the e-learner plays the video, the order of appearance in the answers are randomize. For example, 1.33A shown on the top of the choices may appear on the bottom $0.75 \mathrm{~A}$ the next time the video is played. This random feature forces the learner to pay attention if the student decides to replay the video for review.

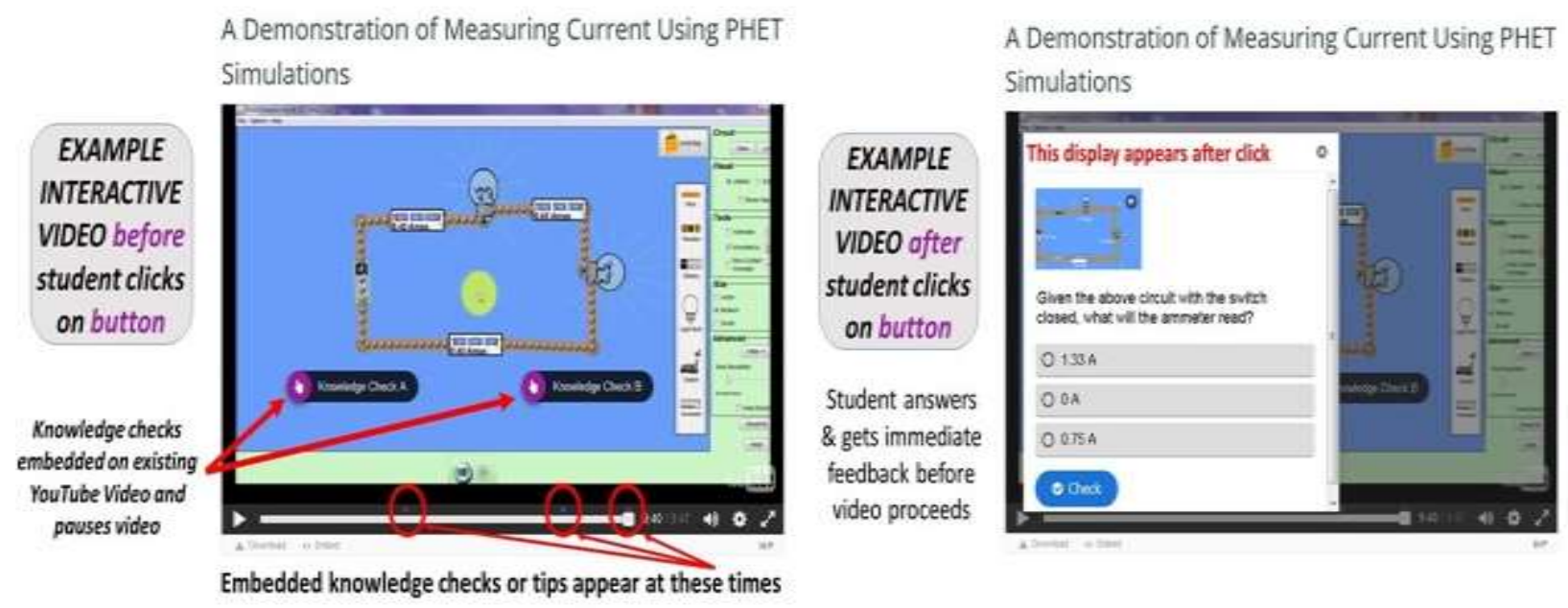

Figure 4. Example of interactive video of screenshots before and after student clicks on knowledge check button

The authors successfully embedded interactive video on the slide using Office Mix. The authors successfully answered questions on top of the video after the video paused. Why implement 
interactive video? Watching a video is basically a passive activity. The authors wanted students to interact with the videos and increase engagement. The authors would like to go beyond the interaction of play, pause, rewind, and stop buttons pressed by the student. The quizzes (the same ones found in Google Docs) were added on top of the YouTube videos. It is important to note that adding the quizzes on the videos did not require redoing the 9 hours of 70-plus videos.

Recently, the authors investigated Visual Basic for Application (VBA). The authors wanted to improve and create ways in delivering interactive content within PowerPoint. The authors found Professor Marcovitz's book, entitled, "Powerful PowerPoint for Educators" 9 . The authors used the book's programming techniques found to create random circuit problems for students to practice. For example, Figure 5 is a screenshot of what is meant of generating random values of circuit components before and after a student clicks an 'ask-a-question' button. After the student clicks the button at the left, a pop-up question and message appears as shown on the right side of Figure 5. In this message, random values for the circuit components are given asking students to enter the calculated value for voltage $V_{1}$ across resistor $R_{1}$. Each time the student clicks on the button, different random values are given. The slide can easily be amended to have the student find the answer using a circuit analysis approach, such as voltage divider or Thevenin equivalent.

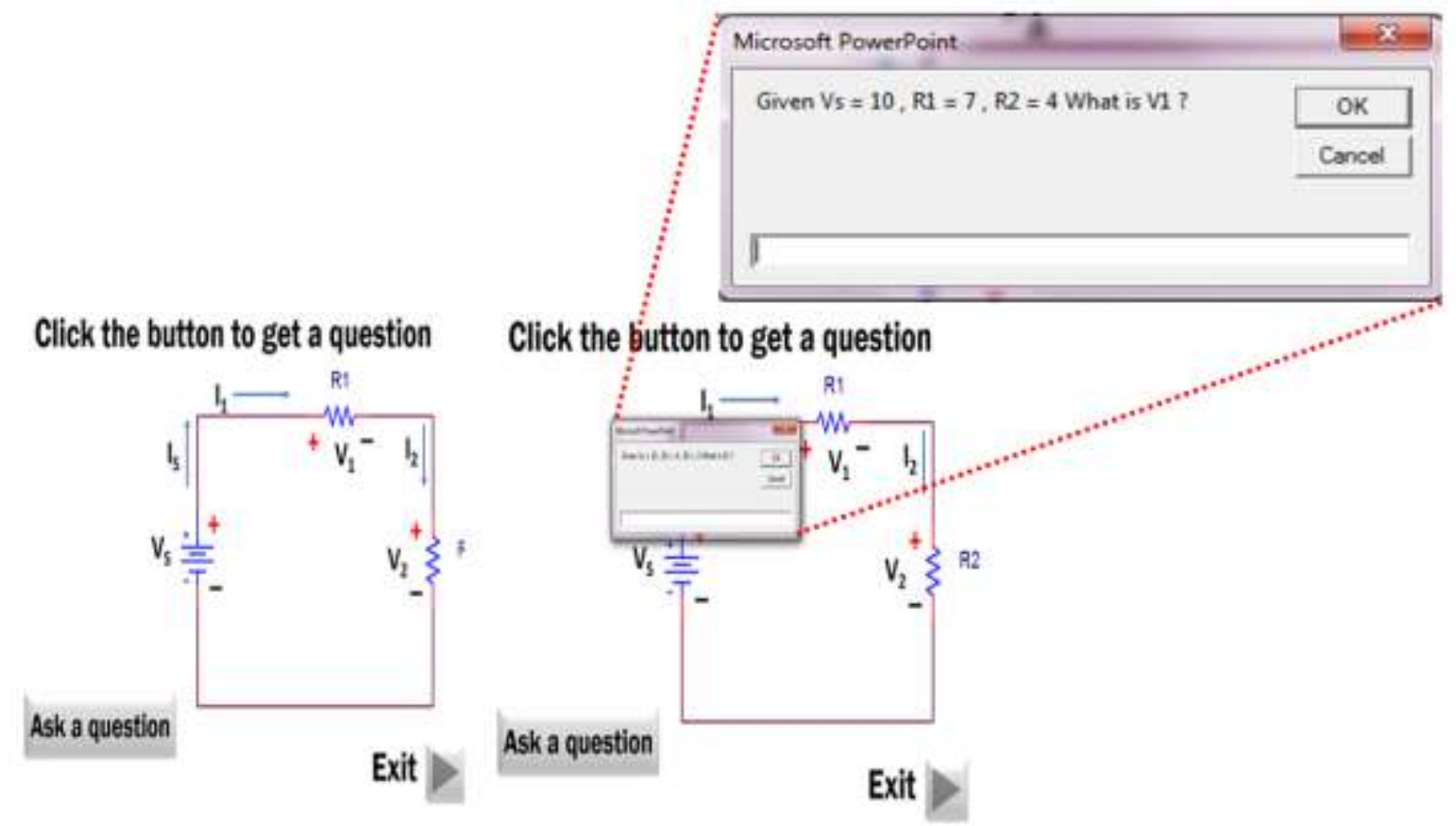

Figure 5. Example of VBA screenshots before and after student clicks on a button to generate another problem with a different set of numbers.

Using VBA in PowerPoint, the authors intend to use Professor Marcovitz's book to record quiz results and deliver the quiz results by email.

\section{Conclusion}

The flipped classroom was successfully implemented during 2016 using innovative methods for EE110. Several various types of multimedia content can be embedded in PowerPoint including 
YouTube Videos. By using Office Mix, the instructor can also embed live webpages with interactions to assess student outcomes on slides. This technique provides a method to present engaging content without jumping between PowerPoint and various websites or applications. This approach can be used for online adaptive learning where students can jump to various points in a presentation according on how well the student performs on solving various problems. With Office Mix, each slide can be viewed as an interactive learning module.

The College of Engineering successfully created engaging multimedia content to deliver a course, 'Introduction to Engineering' in support on a flipped classroom for online delivery. Past survey results show the online flipped classroom as defined by the College of Engineering show promising results ${ }^{1-4}$. Base on the student feedback during the past year, there was a good mix between online video and text. The full-time faculty gained valuable experience and insights producing in multimedia content using PowerPoint beyond the traditional text-based content. The engineering department anticipates the development of future courses will result in shorter timelines as more online courses are implemented in the future.

Several teaching innovations have been presented. The interactive features of Camtasia, the Microsoft's Office Mix plug-in, and the advancement of video players embedded on websites provide opportunities for instructors to rethink their delivery of content in creative ways. Although the full-time faculty learned how to develop technical content for online learners, there is still much to learn. Learning engineering is already a challenge for most self-motivated students. So why not serve and reward them with engaging and interactive content that enriches their learning experience.

\section{References}

1. Santiago, John and Jing Guo, "Leveraging Internet Marketing Technologies and Green-Screen Techniques for Developing Engaging STEM and Online Content”, ASEE Rocky Mountain Section Conference, Cedar City, Utah, 2016

2. Guo, Jing and John Santiago, "Flipped Classroom Method in Teaching "Introduction to Engineering" Course Online, ASEE Rocky Mountain Section Conference, Cedar City, Utah, 2016

3. Guo, Jing, Kathy Kasley and John Santiago, The Challenges of Teaching Engineering Lab Online, 2016 ASEE Rocky Mountain Section Conference, Cedar City, Utah, 2016

4. Jennifer Daines, Tanya Troka and John Santiago, Improving Performance in Trigonometry and Pre-Calculus by Incorporating Adaptive Learning Technology into Blended Models on Campus, 123rd Annual ASEE Conference \& Exposition, New Orleans, Louisiana, 2016

5. "Online Learning is Different, Harvard Study", retrieved from https://www.sciencedaily.com/releases/2013/04/130404122240.htm, Harvard University, April 4,

6. Clark, Ruth, Frank Nguyen and John Sweller, "Efficiency in Learning - Evidence-Based Guidelines to Manage Cognitive Load, Pfeiffer. 2006

7. Clark, Ruth, Richard E. Mayer, "E-Learning and the Science of Instruction - Proven Guidelines for Consumers and Designers of Multimedia Learning, Third Edition, Pfeiffer, 2011

8. Carey, Benedict, "How We Learn - The Surprising Truth About When, Where, and Why It Happens", Random House, 2014

9. Marcovitz, David M., "Powerful PowerPoint For Educators -Using Visual Basic for Applications to Make PowerPoint Interactive”, Second Edition, Libraries Unlimited (ABC-CLIO, LLC), Santa Barbara, CA, 2012.

10. Retrieved from http://phet.colorado.edu. 